INTERNATIONAL JOURNAL OF ENGINEERING, SCIENCE AND TECHNOLOGY

www.ijest-ng.com

\title{
A multiple choice decision analysis: an integrated QFD - AHP model for the assessment of customer needs
}

\author{
F. De Felice ${ }^{1}$, A. Petrillo ${ }^{2 *}$ \\ ${ }^{I}$ Department of Mechanism, Structures and Environment, University of Cassino, Faculty of Engineering, ITALY \\ ${ }^{2 *}$ Department of Mechanism, Structures and Environment, University of Cassino, Faculty of Engineering, ITALY \\ Corresponding Author: e-mail: a.petrillo@ unicas.it, Tel +39-0776-2994350, Fax.+39-0776-2994349
}

\begin{abstract}
The aim of this work is to propose a new methodological approach to define customer specifications through the employment of an integrated Quality Function Deployment (QFD) - Analytic Hierarchy Process (AHP) model. The model, which is loosely based on QFD, incorporates the AHP approach to delineate and rank the relative importance weight of expressed judgments for customer needs and functional characteristics. The Analytic Hierarchy Process is very useful for this aim because it is a mathematically rigorous, proven process for prioritization and decision-making. By reducing complex decisions to a series of pair-wise comparisons, then synthesizing the results, decision-makers arrive at the best decision with a clear rationale for that decision. The methodology adopted in this work is directed to evaluate as well as rank the definition of the customer's needs and functional characteristics among several alternatives. The approach has been validated in a real case study concerning the filter in ceramic material production.
\end{abstract}

Keywords: Quality Function Deployment, Analytic Hierarchy Process, Multi Criteria Decision Analysis.

\section{Introduction}

The aim of this study is to propose a new methodological approach to state the functional characteristics of a ceramic filter in order that it might be competitive as regards performance and price. Owing to this aim, the application of the QFD-AHP seemed to be a very good approach to improve the definition of the customers' needs during the planning phase. Once established a consistent and finite set of functions it is essential to define a hierarchy of importance to determine the criticality of each one, proportional to the function for the customer. We therefore defined an algorithm that, by direct comparison of functions can define a prioritized list that is objective, scientific and unique. In this, AHP is very useful because it is an algorithm that helps to solve decision problems such as MCDA - Multiple Choice Decision Analysis (Saaty, 2005). There are many MCDA methods that have been developed such as ELECTRE, TOPSIS, AHP, etc., but these methods do not consider the interdependence among criteria and alternatives (Lin et al., 2008). Contrarily to other methods, AHP, given a number $n$ of functions, allows to define the importance for customers through a direct and objective value of each function and of all the others. This occurs within a matrix of assessment in which the functions appear on both axes.

We note that the risk usually involved in industrial programmes is not always caused by the possibility of technical unsuccess, but by the probability of obtaining a result that, although scientifically valid, might not be worthwhile for the customer (De Felice, Petrillo, 2009). Thus, the new methodological approach allows to pilot effectively all the variables concurring in the process of generation of the "value" of the product, so as to obtain both the customer's approval and the control of costs. The QFD - AHP method is very flexible and allows to analyse any customer's requirement with impartiality and effectiveness. In particular, it permits to identify the customer's actual "needs" and to focus the technical activity on the output much more in demand. Therefore, it is possible to establish the priority characteristics of the output on an objective basis. As a consequence, the operating units taking part in the project can firstly identify the technical strategies for the achievement of each output, and afterwards assess the needs and thus plan the activities. At the end of our study the company set up an instrument permitting it to take part, with its home and foreign customers, in the development of the products with the consequent reduction in times and costs. The paper is 
organized as follows: in section 2, the survey of existing literature about integration on QFD - AHP is analyzed, the process production of a ceramic filter is described in section 3, QFD and AHP theoretical basis are analyzed in section 4. Finally the model and the case study are proposed in section 5 .

\section{Survey of existing literature about integration on QFD - AHP}

Due to its wide applicability and ease of use, the Analytic Hierarchy Process (AHP) has been studied extensively for the last 20 years. Recently, it has been observed that focus has been confined to the applications of the integrated AHPs rather than the standalone AHP (Ho, 2008). The five tools that are commonly combined with the AHP include mathematical programming, quality function deployment (QFD), meta-heuristics, SWOT analysis, and data envelopment analysis (DEA).

In our study we would like to focus attention on QFD-AHP integration. QFD determines product design specifications (hows) based on customer needs (whats) and competitive analysis (whys), which represent a customer-driven and market-oriented process for decision-making. It is quite natural to use QFD in this field for purposes such as determining customer needs and development priorities. Essentially, QFD has been widely applied to the major aspects of decision-making: measurement, selection/determination, and evaluation. In particular, we analyzed some works during 1998-2009. Major applications concern: Higher education sectors, Manufacturing sectors, Military sectors, Logistics sectors, Sports sectors with particular attention to: Education requirement selection, Teaching method selection, Product design selection, Capital budgeting project selection, Peacekeeping force composition selection, Multi-functional team selection, Facility location selection, Game rule selection, Robot selection, Rapid tooling process selection, Tourism, Competitive benchmarking (Köksal and Eğitman, Lam and Zhao, 1998; Partovi, 1999; Chuang, 2001; Hsiao, Kwong and Bai, 2002; Bhattacharya et al., 2005; Hanumaiah et al., 2006; Dan et al. 2007; Lin et. al., 2008; Li et al., 2009). Recently, also Ho (2008) proposed that the combination of AHP and QFD is one of the most commonly used techniques to deal with incomplete and imprecise information in customer requirements.

In Table 1 a synthetic report about major applications is shown. Of course analysis is not exhaustive, but it is representative.

Table 1. Synthetic report about major applications on QFD-AHP

\begin{tabular}{|c|c|c|}
\hline Year & Author/s & Applications \\
\hline 1998 & $\begin{array}{l}\text { Köksal and Eğitman } \\
\text { Lam and Zhao }\end{array}$ & $\begin{array}{l}\text { Köksal and Eğitman applied the combined AHP-QFD approach to improve the } \\
\text { education quality and to identify appropriate teaching techniques. The } \\
\text { alternative teaching techniques were prioritized based on the AHP weightings } \\
\text { and the relationship between students' requirements and teaching techniques. }\end{array}$ \\
\hline 1999 & Partovi & $\begin{array}{l}\text { Applied the combined AHP-QFD approach to aid the project selection. The } \\
\text { author used the AHP to quantify the strength of the relationships between rows } \\
\text { (e.g., customer requirements) and columns (e.g., design specifications), instead } \\
\text { of evaluate the relative importance weightings of decision alternatives. }\end{array}$ \\
\hline 2001 & Chuang & $\begin{array}{l}\text { Applied the combined AHP-QFD approach to deal with the facility location } \\
\text { problem. The AHP was applied again to determine the relative importance } \\
\text { weightings of alternative locations with respect to each evaluating criterion. A } \\
\text { location with the total highest score was selected. }\end{array}$ \\
\hline 2002 & $\begin{array}{l}\text { Hsiao } \\
\text { Kwong and Bai }\end{array}$ & $\begin{array}{l}\text { Used the combined AHP-QFD approach to aid the new product development. } \\
\text { The AHP was used to obtain the relative importance weightings of the criteria. }\end{array}$ \\
\hline 2005 & Bhattacharya et al. & $\begin{array}{l}\text { Applied the combined AHP-QFD approach to aid the robot selection. The AHP } \\
\text { was adopted to evaluate the relative importance weighting of each robot based } \\
\text { on the technical requirements. The robot with the highest score was selected. }\end{array}$ \\
\hline 2006 & Hanumaiah et al. & $\begin{array}{l}\text { Presented the combined AHP-QFD approach to deal with the rapid tooling } \\
\text { process selection. The AHP was adopted to determine the relative importance } \\
\text { weightings of the tooling or customer requirements while considering } \\
\text { constraints, such as material, geometric features, die material, and production } \\
\text { quantity. }\end{array}$ \\
\hline 2007 & Das et al. & $\begin{array}{l}\text { Developed an AHP-QFD framework for designing a tourism product, which } \\
\text { takes care of the touristic needs of tourists. }\end{array}$ \\
\hline 2008 & Lin et al. & $\begin{array}{l}\text { Evaluated the relative overall importance of customer requirements and design } \\
\text { characteristics. }\end{array}$ \\
\hline 2009 & Li et al. & $\begin{array}{l}\text { Combining rough set theory, Kano's model, analytical hierarchy process (AHP), } \\
\text { and scale method, an integrated method is proposed to obtain the final } \\
\text { importance of customer requirements (CRs) in product planning house of } \\
\text { quality (PPHOQ). }\end{array}$ \\
\hline
\end{tabular}


Some papers (Partovi, 1999) have applied the ANP combined with the QFD to handle MCDM problems, but they do not entirely utilize the AHP in their models. Our proposed method completely utilizes all natures of the AHP to make all paired comparisons based on Saaty's nine-point scale to evaluate the customer's needs and functional characteristics among several alternatives.

The use of AHP is favorable because the AHP provides an effectual method to cope with complex MCDM matters. The AHP has advantages such as: it handles human intuitive judgment by making paired comparisons with a ratio scale. In other words, the AHP adds benefits in that it can capture priorities using natural language comparisons and converts them into ratio scale numbers.

\section{Filters in ceramic material: Process description}

The filter market is divided into sections defined by the different functions of the use of the product (the filters, in fact, can be used: to catalyze, to filter aluminium alloys or treat them from fused to filter metals, to filter air at high temperatures, as insulators for high temperatures, as heat exchangers, in fire-blockings, in water treatments, etc) and by various types of users (De Felice, Falcone, 1999). Within such a variegated framework the company has focused on ceramic foam filters, because, compared to the traditional ones, they allow to obviate some disadvantages, such as:

- Encumbrance.

- High energy consumption.

- Insufficient operating flexibility.

- Limited productivity due to the dead times of change of the filter bed.

The filtering system suggested by the company employs a ceramic foam as filtering element with a continuous net of pores. It is a structure showing the following characteristics:

- Resistance to high temperatures.

- Low specific weight.

- Resistance to chemical attacks and winding flows.

- High porosity.

Thanks to these properties, the ceramic foam with open pores can satisfy various types of demands for different uses. Besides, the structure of the ceramic foam can be "thin" or "thick" according to the number of pores per linear inch.(p.p.i.). The factory produces ceramic foams varying from a size of 10 pores per inch to 100 p.p.i. and over. The production technique of the ceramic foam filters is simple. In fact, a polyurethane foam with open pores is used as a base of the filter. The foam is soaked with a watery alumina pulp. The overplus of alumina is sqeezed so that the foam may result completely covered. With a drying process the water is eliminated from the foam, which decomposes later, at the stated temperature, leaving a ceramic copy of the original organic foam. The filter production process consists of:

1. Production of sheets of polyurethane.

2. Wash sponge.

3. Impasto preparation.

4. First dip sponge.

5. Preliminary drying.

6. Second dip sponge.

7. Second drying.

8. Cooking Filter.

9. Packaging.

\section{Theoretical Basis: Quality Function Deployment and Analytic Hierarchy process}

In this paper, we employ a combined QFD and AHP approach to develop an effective decision-making method to help make better decisions for planning or evaluation problems (Chin et. al., 2009). Both QFD and AHP are the comprehensive decisionmaking method that provides a means of coping with complex MCDM matters. The QFD is an overall concept that provides a means of translating customer requirements into the appropriate technical requirements for each stage of product development and production. The QFD methodology can be used for both tangible products and non-tangible services, including manufactured goods, service industry, software products, IT projects, business process development, government, healthcare, environmental initiatives, and many other applications. The AHP is a MCDM method used to derive relative priority from individual judgments, which can deal with all kinds of interactions systematically (Chan et. al, 2002). In this section we will briefly explain the traditional QFD and AHP framework.

4.1 Quality Function Deployment Approach: In this section we will briefly explain the traditional QFD framework as it is commonly discussed in the quality management literature. The birth of QFD can be placed around 1972, when Takayanagi Nishimura and his engineers presented a quality chart for a shipyard in Kobe in Japan. The aim of QFD is to translate the customer requirements to the product requirement (Juran, 1993). In other words, QFD is a tool for transforming the "Voice of customer" to 
product design (Cohen, 1995). As experiment they used a matrix in which customer needs were reported in lines and methods to satisfy them in columns. The idea was that the matrix must gradually fill on the basis of extensive discussions between Marketing Manager, Design Manager and Production Manager. This collaboration is the fundamental difference between QFD and previous methods. Two years later, Professor Yoji Akao founded and directed a Research Committee on QFD (Akao, 2003). He oversaw the dissemination of QFD as a technique for improving the transition from design to production. We define the Quality Function Deployment (QFD) tool for the development of products starting from customer needs, resulting in a systematic technical specifications which are a guide to manufacturing activities. QFD translates customer requirements into appropriate specifications within the company in each of its functional areas, from research and development to engineering, manufacturing, distribution, sales and service. The logical process that underlies the development of new products with the QFD can be enclosed in a matrix, to describe it briefly, we refer to the matrix of quality (one fundamental matrix of QFD) called House of Quality. This matrix has the appearance of a tiled roof, hence the name "house of quality"(Chen, 2009).

According to Cohen (1995) and Han (2001), there are six stages of the hierarchical framework of QFD as follows (Figure 1):

1. Voice of customer - developing, categorizing and prioritizing customer requirements.

2. Competitive analysis - comparing the performances with competitors and set target levels for customer requirements.

3. Voice of organization - translating the voice of customers to the voice of organization.

4. Design Targets - specifying target values for design requirements and determining the project costs.

5. Relationship Matrix - evaluating impact of design requirements on customer requirements.

6. Correlation Matrix - specifying tradeoffs and selecting the appropriate design requirement.

The structure of the house of quality is outlined in the following figure (Figure 1). We note that in this matrix there are 6 different areas.

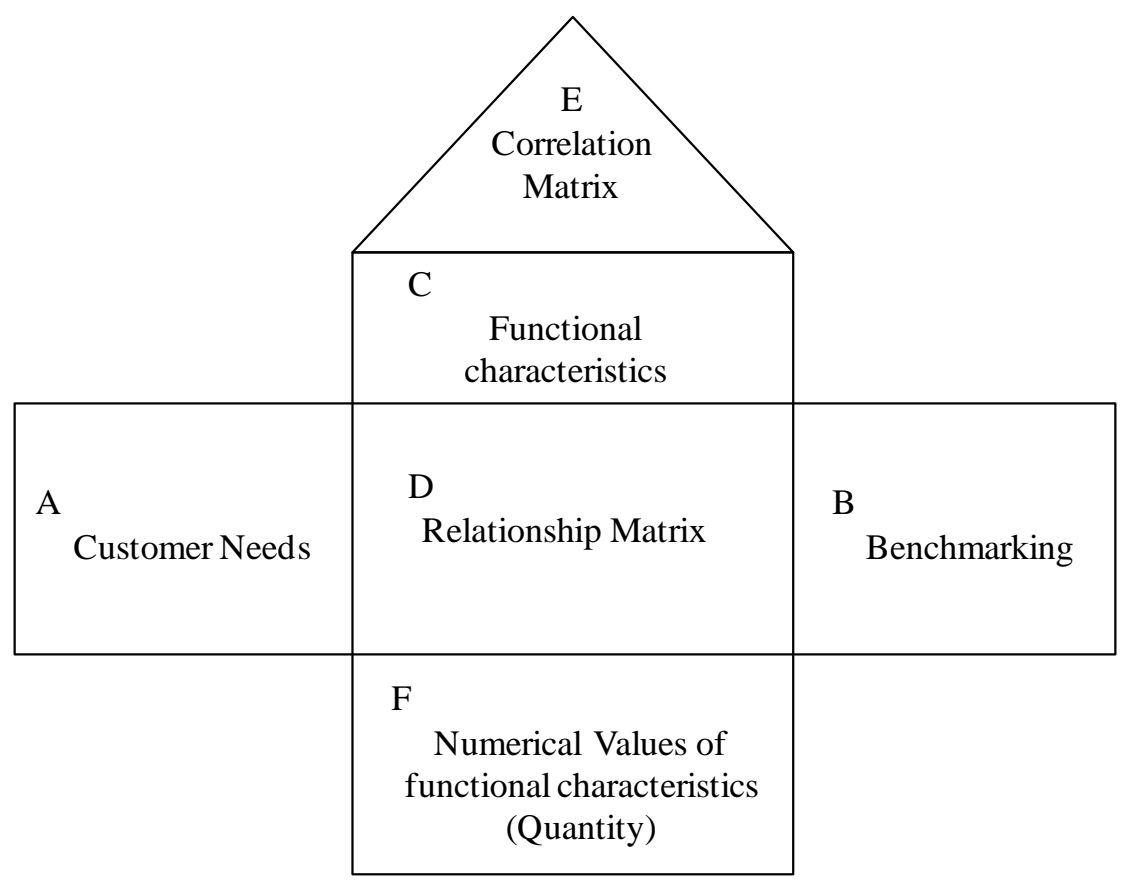

Figure 1. House of Quality

The motivation of planning house of quality is designing a product that embedded as well as possible the initial, potential abstract, customer requirement (Chan \& Wu, 2005; Ramanathan \& Jiang, 2009). QFD improves quality while reducing costs, this obviously makes it more competitive in business. It is created to solve three problems: inattention to the voice of the customer; loss of information during the course of the product along the development cycle; different interpretations of the specifications by the various departments involved.

In general, QFD facilitates organization: 1) understanding the actual requirements of customers, 2) prioritizing customer requirements in order of importance from the customer's point of view, 3) communicating among team members in order to ensure decision making and reducing loss of data, 4) designing the products which meet or exceed customer requirements, 5) planning or selecting the product design strategically (Han, 2000; Cohen, 1995).

4.2 Analytic Hierarchy Process Approach: AHP uses an interactive hierarchical structure for multi-objective decision-making (MODM) developed by Saaty (Saaty, 1980). AHP is the one of the most systematic analytical techniques of MCDM within the 
framework of operational research techniques that facilitates a rigorous definition of priorities and preferences of DMs. The AHP consists of three main operations, including hierarchy construction, priority analysis and consistency verification.

The methodology combines both qualitative and quantitative approaches. In the qualitative sense, it decomposes an unstructured problem into a systematic decision hierarchy. It then uses a quantitative way to employ pair-wise comparison to determine the local and global priority weights and the overall ranking of the alternatives. The methodology quantifies the qualitative factors with a scale called Saaty's nine- point scale (see Table 2).

Table 2. The fundamental Scale proposed by Saaty

\begin{tabular}{|c|l|l|}
\hline $\begin{array}{c}\text { INTENSITY OF } \\
\text { IMPORTANCE } \mathbf{a}_{\mathbf{i j}}\end{array}$ & \multicolumn{1}{|c|}{ DEFINITION } & \multicolumn{1}{c|}{ EXPLANATION } \\
\hline 1 & Equal Importance & Two activities contribute equally to the objective \\
\hline 3 & Moderate importance & Experience and judgment slightly favor one activity over another \\
\hline 5 & Strong importance & $\begin{array}{l}\text { Experience and judgment strongly favor one activity over } \\
\text { another }\end{array}$ \\
\hline 7 & $\begin{array}{l}\text { Very strong or } \\
\text { demonstrated importance }\end{array}$ & $\begin{array}{l}\text { An activity is favored very strongly over another; its dominance } \\
\text { demonstrated in practice }\end{array}$ \\
\hline 9 & Extreme importance & $\begin{array}{l}\text { The evidence favoring one activity over another is of the highest } \\
\text { possible order of affirmation }\end{array}$ \\
\hline $2,4,6,8$ & $\begin{array}{l}\text { For compromise between } \\
\text { the above values }\end{array}$ & $\begin{array}{l}\text { Sometimes one needs to interpolate a compromise judgment } \\
\text { numerically because there is no good word to describe it }\end{array}$ \\
\hline
\end{tabular}

After establishing pair-wise comparison, a pair-wise comparison matrix is established. The matrix is called $\mathrm{A}=$ (aij). This matrix is constructed with respect to a particular property the elements have in common. It is reciprocal, that is, aij $=1 / a \mathrm{aj}$; There are $\mathrm{n}(\mathrm{n}$ -1 ) / 2 judgments required for a matrix of order $n$. We note that when you express judgments on comparisons in pairs inconsistent judgments are formed, as the human mind has the inability to simultaneously take into account all the relations between the terms of the comparison (Saaty, 2001). It is necessary to identify the degree of inconsistency that can be considered tolerable. In mathematical terms, the verification of consistency is expressed through the calculation main eigenvalue $\lambda_{\max }$ : if the value is $n$ then the matrix (of rank $n$ ) is consistent. More $\lambda_{\max }$ is equal to the number $n$ more consistent is the result. The deviation of the coherence is shown with the index of consistency (I.C.):

$$
\text { I.C. }=\left(\lambda_{\max }-n\right) /(n-1)<0.10
$$

where $\mathrm{n}$ is the number of components evaluated in the pairwise comparison matrix, and $\lambda_{\max }$ is the largest eigenvalue characterizing the previous matrix. When the calculated CR values exceed the threshold, it is an indication of inconsistent judgment. In such cases, the decision makers would need to revise the original values in the pairwise comparison matrix. Finally, it is necessary to aggregate the relative priorities of the decision elements to obtain an overall rating for decision alternatives. The numerical analysis method is employed to calculate the eigenvalue vector and the maximized eigenvalue for an understanding of the consistency established and the relative weight among elements.

\section{Integration QFD - AHP: The model and case study}

In order to work correctly to determine customer needs and design characteristics, an inter functional team was set up. It was composed of 2 delegates from the 5 main departments of the firm (commercial, technical, production, quality and purchase departments). The solutions are designed in groups by using morphological analysis and the brainstorming technique. This team gave a description of the needs that a customer expects to satisfy through the purchase of the product of the firm. This procedure was repeated for the different groups, who, after working autonomously for 4 weeks, confronted one another trying to agree upon a definite list of the customer's needs. After sharing the list, the groups were set up again, and together defined a pooled ranking for the customer's needs and functional characteristics with the AHP methodology (see step 1). In Figure 2 methodological steps of the QFD-AHP approach are illustrated. 


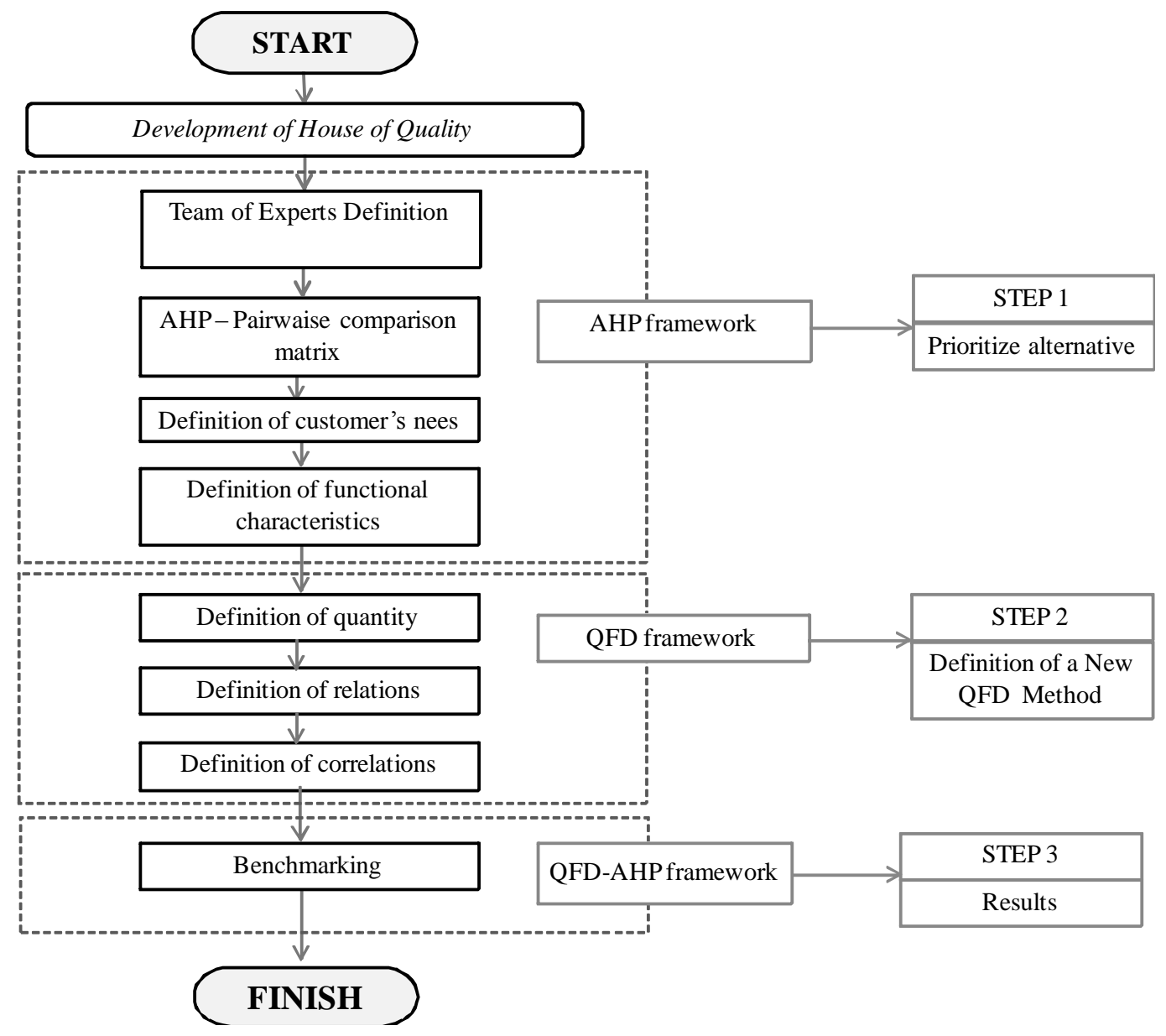

Figure 2. Methodological steps of QFD-AHP approach

Step 1: Prioritize Alternatives. The team of experts defined with the help of the AHP methodology the needs and functional characteristics that a customer expects to satisfy through the purchase of the product of the firm. Using AHP a sample question used here would be "How much more important is Certification than Cost of raw material with respect to the Functional characteristics?" The outcome of this evaluation is a set of weights representing the relationships between elements. The result of this work is shown in the following Table 3 and Table 4.

Table 3. AHP priority vector for customer's needs

\begin{tabular}{|l|c|c|c|}
\hline \multicolumn{1}{|c|}{ Customer's need } & Identification Code of Customer's needs & AHP Priority vector - weight & Order \\
\hline Filtering power & A & 0.28 & $1^{\circ}$ \\
\hline Capacity of regulating the flow & B & 0.22 & $3^{\circ}$ \\
\hline Lifetime & C & 0.23 & $2^{\circ}$ \\
\hline Dimensional specification of coupling & D & 0.05 & $5^{\circ}$ \\
\hline Product certified & E & 0.12 & $4^{\circ}$ \\
\hline Competitive price & F & 0.07 & $6^{\circ}$ \\
\hline
\end{tabular}

Table 4. AHP priority vector for functional characteristics

\begin{tabular}{|l|c|c|c|}
\hline Functional features & $\begin{array}{c}\text { Identification Code of } \\
\text { Customer's needs }\end{array}$ & $\begin{array}{c}\text { AHP Priority vector - } \\
\text { weight }\end{array}$ & Order \\
\hline Filtering degree & A & 0.08 & $5^{\circ}$ \\
\hline Thermic resistance & B & 0.10 & $4^{\circ}$ \\
\hline Mechanical resistance & C & 0.21 & $2^{\circ}$ \\
\hline Dimension & D & 0.19 & $3^{\circ}$ \\
\hline Certification & E & 0.35 & $1^{\circ}$ \\
\hline Cost of raw materials & F & 0.04 & $6^{\circ}$ \\
\hline
\end{tabular}


Step 2: Definition of a new QFD method of aid for the creation of the correlation matrix. Then, through the application of the QFD a complete and appropriate transfer of the needs which pointed out into measurable functional characteristics was established, so as to make a table, in which these functional characteristics are compared with the simple needs of the customer. Therefore 3 degrees of correlation are established conventionally by suitable factors: $3=$ strong; $2=$ average; $1=$ weak. If there are no connections, the corresponding crossings in the matrix are left empty. The correlation factors and the allotment of the priorities to the requisites allowed to establish a classification of the characteristics according to their importance (Figure 3).

\begin{tabular}{|c|c|c|c|c|c|c|c|}
\hline \multirow[b]{2}{*}{$\begin{array}{l}\text { degree of correlation between } \\
\text { needs and characteristics } \\
3 \text { STRONG } \\
2 \text { MEDUM } \\
1 \text { WEAK } \\
\end{array}$} & weight & 0.08 & 0.10 & 0.21 & 0.19 & 0.35 & 0.04 \\
\hline & 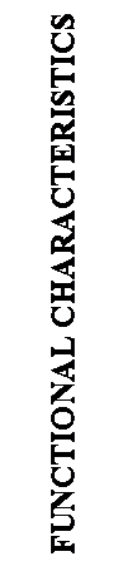 & 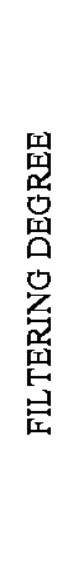 & 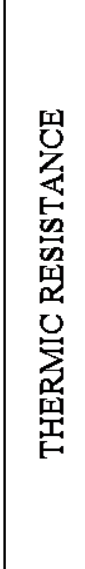 & 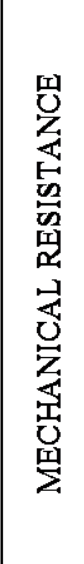 & 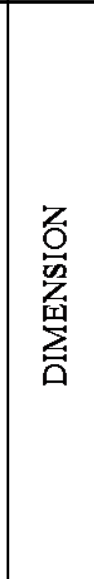 & 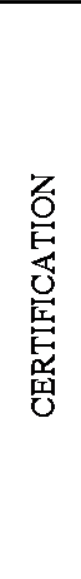 & 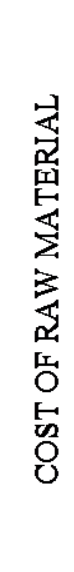 \\
\hline CUSTOMER'S NEEDS & weight & $C 1$ & C2 & $C_{3}$ & $c 4$ & $c_{5}$ & C6 \\
\hline FILTERING POWER & 0.28 & 3 & 2 & 2 & 1 & 2 & \\
\hline CAPACITY OF REGULATING THE FLOW & 0.22 & 3 & 1 & 2 & 2 & 2 & \\
\hline LIFETIME & 0.23 & & 3 & 3 & & 2 & \\
\hline DIMENSIONAL SPECIFICATION OF COUPLING & 0.05 & & & & 3 & & \\
\hline PRODUCT CERTIFIED & 0.12 & & & & & 3 & \\
\hline COMPETITIVE PRICE & 0.07 & & 2 & 2 & 2 & 1 & 3 \\
\hline & 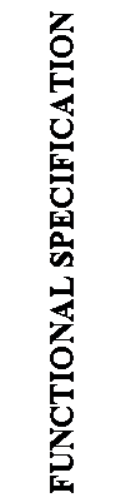 & 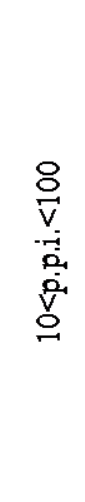 & $\begin{array}{l}0 \\
\circ \\
8 \\
8\end{array}$ & 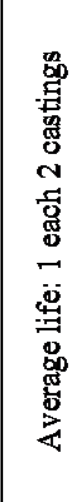 & 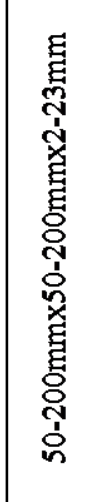 & Б & 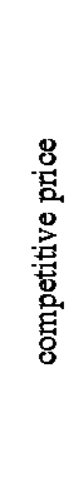 \\
\hline & & & & & & & \\
\hline
\end{tabular}

Figure 3. Correlation matrix

The functional characteristics are still a matter for the realization of another table; the correlations between these characteristics are pointed out by using suitable factors (Figure 4). 


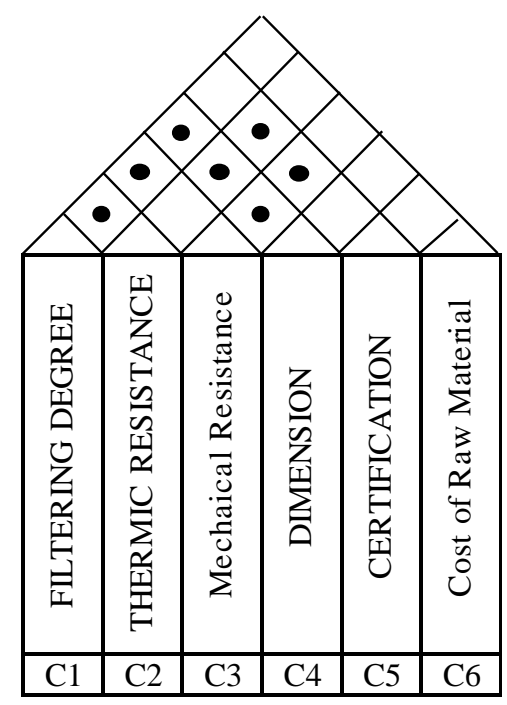

Figure 4. Correlations between functional characteristics

In order to make the definition of the correlations among the different functional requisites pointed out as objective as possible, we set up a system to express the correlation table automatically, making the planner intervene only when necessary to establish the "sign" of the correlations themselves. Before going on with the description of the algorithm, it is necessary to define the terms "correlation" and "sign" of the correlations. Within the QFD, two functional characteristics are said to be correlated if the variations of the values of one cause changes in the values of the other and viceversa. and, on the contrary, the sign of such correlations is positive, if to the "positive" variations of one correspond "positive" changes of the other, "negative" if otherwise. In order to define the relations existing (induced by the requisites) between functional characteristics, it is necessary to take into consideration the Relationship Matrix R (House of Quality - area D). Here below is Relationship Matrix R (figure 5):

$$
R=\left|\begin{array}{llllll}
3 & 2 & 2 & 1 & 2 & 0 \\
3 & 1 & 2 & 2 & 2 & 0 \\
0 & 3 & 3 & 0 & 2 & 0 \\
0 & 0 & 0 & 3 & 0 & 0 \\
0 & 0 & 0 & 0 & 3 & 0 \\
0 & 2 & 2 & 2 & 1 & 3
\end{array}\right|
$$

Figure 5. Relationship Matrix R

It is also necessary take into consideration all the vectors (Matrix B) taken together in $b_{i}$ column (each combined with a well defined functional characteristic expressed in the matrix of the relations R). Here below is Matrix B (Figure 6):

$$
B=\left|\begin{array}{llllll}
1 & 1 & 1 & 1 & 1 & 0 \\
1 & 1 & 1 & 1 & 1 & 0 \\
0 & 1 & 1 & 0 & 1 & 0 \\
0 & 0 & 0 & 1 & 0 & 0 \\
0 & 0 & 0 & 0 & 1 & 0 \\
0 & 1 & 1 & 1 & 1 & 1
\end{array}\right|
$$

Figure 6. B Matrix 
The elements of the vectors $\mathrm{b}_{\mathrm{i}}(\forall=1, \ldots, \mathrm{n})$ have been defined starting from Relationship Matrix $\mathrm{R}$ in the following manner (Equation 2):

$$
\forall i, j \text { if } r_{i j}=\text { " } 3 \text { " or " } 2 \text { ” or “ } 1 \text { ”, then } b_{i j}=1
$$

Thus, from $\mathrm{R}$ matrix, we then pass to a B binary matrix, whose $\mathrm{b}_{\mathrm{i}}$ columns are afterwards standardized in order to make their interpretation easier, so as to obtain a new set of $\mathrm{v}_{\mathrm{i}}$ vectors $(\forall=1, \ldots, \mathrm{n})$ which define a new $\mathrm{N}$ matrix (Figure 7):

$$
N=\left|\begin{array}{cccccc}
\frac{1}{\sqrt{2}} & \frac{1}{2} & \frac{1}{2} & \frac{1}{2} & \frac{1}{\sqrt{5}} & 0 \\
\frac{1}{\sqrt{2}} & \frac{1}{2} & \frac{1}{2} & \frac{1}{2} & \frac{1}{\sqrt{5}} & 0 \\
0 & \frac{1}{2} & \frac{1}{2} & 0 & \frac{1}{\sqrt{5}} & 0 \\
0 & 0 & 0 & \frac{1}{2} & 0 & 0 \\
0 & 0 & 0 & 0 & \frac{1}{\sqrt{5}} & 0 \\
0 & \frac{1}{2} & \frac{1}{2} & \frac{1}{2} & \frac{1}{\sqrt{5}} & 1
\end{array}\right|
$$

Figure 7. N Matrix

To represent the effects of the dependence between the $\mathrm{i}$-nth and the $\mathrm{j}$-nth characteristics, we introduce the note $\mathrm{q}_{\mathrm{ij}}($ Equation 3 ):

$$
\mathrm{q}_{\mathrm{ij}}=\mathrm{v}_{\mathrm{i}} \bullet \mathrm{v}_{\mathrm{j}}=\cos \left(\mathrm{v}_{\mathrm{i}}, \mathrm{v}_{\mathrm{j}}\right) \quad \forall \mathrm{ij}=1, \ldots, \mathrm{n}
$$

Effecting the calculation of $\mathrm{q}_{\mathrm{ij}}$ for all the vector couples of $\mathrm{N}$ matrix, it is possible to determine the matrix of the dependences of the Q characteristics: $Q=N N^{T}$ (Q is a symmetrical matrix with $\mathrm{q}_{\mathrm{ij}}=\mathrm{q}_{\mathrm{ji}} ; \mathrm{i}=\mathrm{j}=1, \ldots, \mathrm{n}$ ). The $\mathrm{Q}$ matrix expresses the degree of dependence induced between functional characteristics with reference to how they influence the customer's requisites. It is interesting to note that the determination of the $\mathrm{Q}$ matrix also permits to underline the presence of columns and /or lines without relations respectively with other lines and/or columns of the same matrix, marked by the appearance of some "zeros" along the principal diagonal of the matrix. For the "filling up" of the roof of the "house of quality", the information contained in Q is

\begin{tabular}{|c|c|c|c|c|c|c|}
\hline & C1 & $\mathrm{C2}$ & C3 & $\mathrm{C4}$ & C5 & C6 \\
\hline C1 & 1 & 0,71 & 0,71 & 0,71 & 0,63 & 0 \\
\hline $\mathrm{C2}$ & 0,71 & 1 & 1 & 0,75 & 0,89 & 0,5 \\
\hline $\mathrm{C3}$ & 0,71 & 1 & 1 & 0,75 & 0,89 & 0,5 \\
\hline $\mathrm{C} 4$ & 0,71 & 0,75 & 0,75 & 1 & 0,67 & 0,5 \\
\hline $\mathrm{C5}$ & 0,63 & 0,89 & 0,89 & 0,67 & 1 & 0,45 \\
\hline C6 & 0 & 0,5 & 0,5 & 0,5 & 0,45 & 1 \\
\hline
\end{tabular}
compared with a $\mathrm{K}$ predefined threshold (with $0<\mathrm{k}<1$ ); $\forall \mathrm{ij}$ if qij $>\mathrm{k}$ the existence of a potential correlation between the $\mathrm{j}$-nth and i-nth characteristics is accepted, otherwise it is considered inexistent. The Q matrix obtained is the following (Figure 8):

Figure 8. Q Matrix

As the table confirms, the $\mathrm{Q}$ matrix is really symmetrical. In the table the values of $\mathrm{q}_{\mathrm{ij}}>\mathrm{k}$ are also pointed out, since, in this particular case, a threshold value of $\mathrm{K}=0.7$ has been fixed. After establishing and pointing out the couples of characteristics whose degree of dependence induced is superior to the $\mathrm{K}$ threshold, it is necessary to estimate the real consistency of the dependence and transfer it into a correlation, defining its positive or negative "sign". So, in this particular case, all the dependences are transferred into a correlation, except the couple $\{\mathrm{C} 1, \mathrm{C} 3\}$ which is rejected since it does not possess the necessary requisites. Finally, semantic correlations must be added to all dependences, defined on the base of quality reasoning. The whole of the correlations identified defines the roof of the house of quality (Figure 9). 


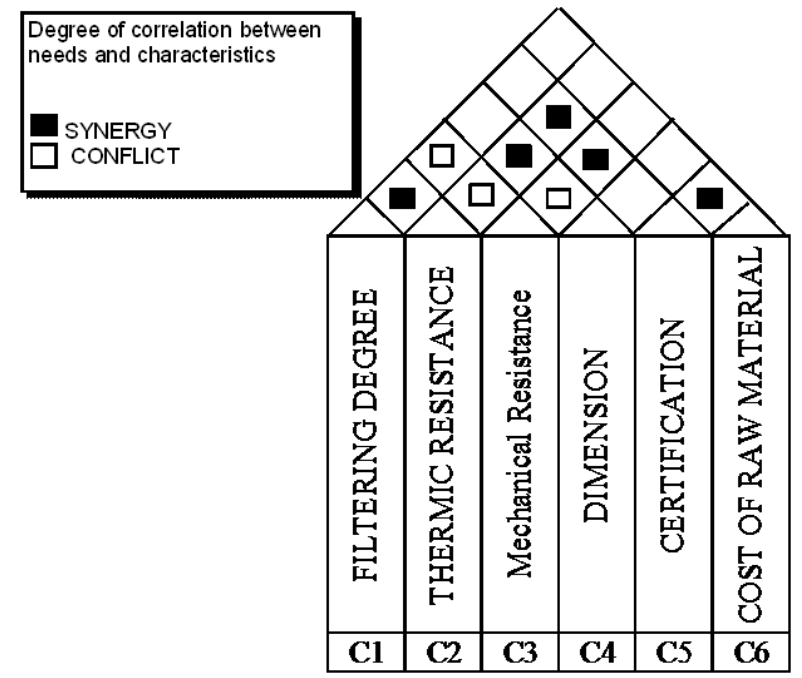

Figure 9. Identification of the roof of the house

Step 3: Benchmarking and Results. Benchmarking started by appraising the ranges of the functional specifications (Table 5).

Table 5. Ranges of the functional specifications

\begin{tabular}{|c|c|c|c|c|c|c|}
\hline 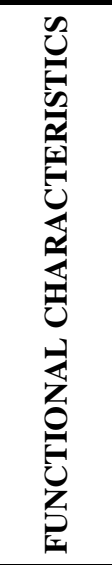 & 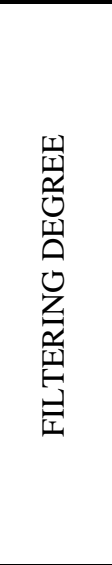 & 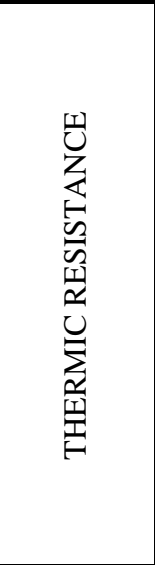 & 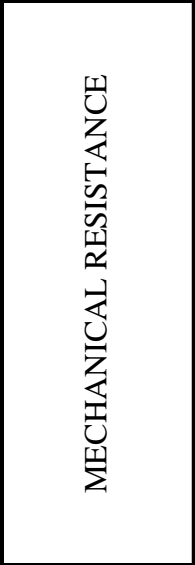 & & 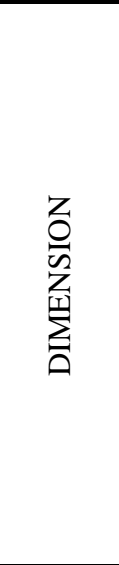 & \\
\hline UNITS & p.p.i. & ${ }^{\circ} \mathbf{C}$ & $\mathbf{n}^{\circ}$ utilizations & & $\mathbf{m m}$ & \\
\hline 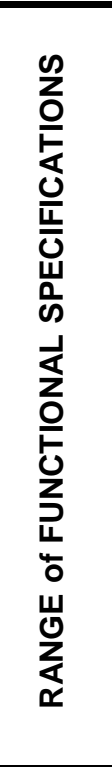 & $\begin{array}{c}10-20 \\
20-30 \\
30-80 \\
80-90 \\
90-100 \\
100-150\end{array}$ & $\begin{array}{c}730-750 \\
750-760 \\
760-780 \\
780-800 \\
800-1000 \\
1000-1050 \\
1050-1100 \\
1100-1150 \\
1150-1200 \\
1200-1250 \\
1250-1300 \\
1300-1320 \\
1320-1360 \\
1360-1380 \\
1380-1400 \\
1400-1440 \\
1440-1460 \\
1460-1500\end{array}$ & $\begin{array}{l}1 \\
2\end{array}$ & $\begin{array}{c}\text { width } \\
10-33 \\
33-50 \\
50-66 \\
66-70 \\
70-75 \\
75-80 \\
80-81 \\
81-90 \\
90-99 \\
99-100\end{array}$ & $\begin{array}{c}\text { length } \\
10-25 \\
25-33 \\
33-50 \\
50-66 \\
66-70 \\
70-75 \\
75-80 \\
80-81 \\
81-90 \\
90-99 \\
99-100 \\
100-114 \\
114-200\end{array}$ & $\begin{array}{c}\text { height } \\
2-3 \\
3-12 \\
12-15 \\
15-20 \\
20-22 \\
22-23\end{array}$ \\
\hline
\end{tabular}


In order to verify the quality of the specifications of the project, a scheme was made which lets allot its value to every project under examination. The project characteristics defined for the Project A (our company) and for Project B (a firm leader in the field of filters) are reported in Table 6.

Table 6. Project evaluation table (C.F. $=$ Functional Characteristics - R.S.F. $=$ Ranges of functional specifications $)$

\begin{tabular}{|c|c|c|c|c|c|c|c|c|}
\hline \multicolumn{9}{|c|}{ TABLE OF VALUATION OF PROJECT } \\
\hline \multicolumn{5}{|c|}{ put the value 1 where appropriate } & \multicolumn{4}{|c|}{ \% FOUNDRIES SATISFIED } \\
\hline \multirow[t]{2}{*}{ weight } & \multirow[t]{2}{*}{ C.F. } & \multirow[t]{2}{*}{ R.S.F. } & \multirow[t]{2}{*}{$\mathbf{A}$} & \multirow[t]{2}{*}{ B } & \multicolumn{2}{|c|}{ Cast Iron } & \multicolumn{2}{|c|}{ Bronze-Brass-Copper-Aluminium } \\
\hline & & & & & $A$ & $\mathbf{B}$ & $\mathbf{A}$ & B \\
\hline 117 & $\mathrm{C} 1$ & $\begin{array}{c}10-20 \\
20-30 \\
30-80 \\
80-90 \\
90-100 \\
100-150\end{array}$ & $\begin{array}{l}1 \\
1 \\
1 \\
1 \\
1\end{array}$ & $\begin{array}{l}1 \\
1\end{array}$ & 83 & 33 & 100 & 70 \\
\hline 168 & $\mathrm{C} 2$ & $\begin{array}{c}730-750 \\
750-760 \\
760-780 \\
780-800 \\
800-1000 \\
1000-1050 \\
1050-1100 \\
1100-1150 \\
1150-1200 \\
1200-1250 \\
1250-1300 \\
1300-1320 \\
1320-1360 \\
1360-1380 \\
1380-1400 \\
1400-1440 \\
1440-1460 \\
1460-1500\end{array}$ & $\begin{array}{l}1 \\
1 \\
1 \\
1 \\
1 \\
1 \\
1 \\
1 \\
1 \\
1 \\
1 \\
1 \\
1 \\
1 \\
1 \\
1 \\
1 \\
1 \\
\end{array}$ & $\begin{array}{l}1 \\
1 \\
1 \\
1 \\
1 \\
1 \\
1 \\
1 \\
1 \\
1 \\
1 \\
1 \\
1 \\
1 \\
1 \\
1 \\
1 \\
1 \\
\end{array}$ & 100 & 100 & 100 & 100 \\
\hline 186 & C3 & $\begin{array}{l}1 \\
2 \\
\end{array}$ & 1 & 1 & 100 & 100 & 100 & 100 \\
\hline
\end{tabular}

It is important to note that the range of functional specifications and the percentage of customers satisfied per section have been supplied by external sampling including firms that are leaders in the field concerning our work and allow to represent all the situations of the Cast Iron Foundries and of Bronze-Brass-Copper-Aluminium Foundries. After defining the value customer for both projects and knowing the relative sale prices, it is possible to estimate their cost per point for the customer. From the comparison of costs it is evident that Project B is better than Project A (Table 7).

Table 7. Comparative overall results

\begin{tabular}{|c|c|c|}
\hline \multicolumn{3}{|c|}{ COMPARATIVE OVERALL RESULTS } \\
\hline & $\mathbf{A}$ & $\mathbf{B}$ \\
\hline Sale price & 1400 & 1300 \\
\hline \multicolumn{3}{|l|}{$\begin{array}{l}\text { VALUE A CUSTOMER } \\
\text { (expressed in points) }\end{array}$} \\
\hline Cast iron foundries & 806,61 & 853,71 \\
\hline Bronze-Brass-Copper-Aluminium foundries & 895 & 874,9 \\
\hline \multicolumn{3}{|l|}{$\begin{array}{l}\text { COST PER POINT FOR THE CUSTOMER } \\
(\epsilon)\end{array}$} \\
\hline Cast iron foundries & 1,74 & 1,52 \\
\hline Bronze-Brass-Copper-Aluminium foundries & 1,56 & 1,49 \\
\hline
\end{tabular}


After these results, an improvement was started for Project A. The improvement was made possible by varying the ranges of specifications connected with the C5 and C4 characteristics which are at the top in the relative hierarchical scale (Table 8).

Table 8. New comparative overall results

\begin{tabular}{|c|c|c|c|}
\hline \multicolumn{4}{|c|}{ COMPARATIVE OVERALL RESULTS } \\
\hline & $\mathbf{A}$ & B & $\mathbf{A}^{*}$ \\
\hline Sale price & 1400 & 1300 & 1400 \\
\hline \multicolumn{4}{|l|}{$\begin{array}{l}\text { VALUE A CUSTOMER } \\
\text { (expressed in points) }\end{array}$} \\
\hline Cast iron foundries & 806,61 & 853,71 & 941,11 \\
\hline Bronze-Brass-Copper-Aluminium foundries & 895 & 874,9 & 927 \\
\hline \multicolumn{4}{|l|}{$\begin{array}{l}\text { COST PER POINT FOR THE CUSTOMER } \\
\qquad(€)\end{array}$} \\
\hline Cast iron foundries & 1,74 & 1,52 & 1,49 \\
\hline Bronze-Brass-Copper-Aluminium foundries & 1,56 & 1,49 & 1,51 \\
\hline
\end{tabular}

The actions set out allowed an increase of the value/customer of Project A and therefore a reduction in the cost per point for the customer. The method proposed permits to simplify the activities of analysis of the information contained in the QFD tables; however, it does not take into consideration the opportunity of inserting more functional characteristics; if these are exhau stive of the problem or if some of these are redundant. Only the planner can give these matters an appropriate answer. Therefore, the method suggested can be used in an interactive manner. Finally, it is interesting to observe how the scheme of valuation of the dependence between functional characteristics can be reproposed for the valuation of possible correlations with the customer's requirements. Further development could be oriented in developing a benchmarking analysis to define the market share of product.

\section{Conclusions}

Complex or important decisions should not be based solely on instinct. Whether prioritizing customer needs in QFD, making budget decisions involving a variety of tangible and intangible strategic goals, managing conflicting stakeholders, or selecting from among dozens or hundreds of alternative initiatives to be pursued, the Analytic Hierarchy Process (AHP) can help managers and developers combine all this information and make informed decisions.

The new methodological approach allows to:

- Align their decisions with their organizational objectives.

- Implement a structured, repeatable and justifiable decision making approach.

- Leverage organizational expertise.

- Improve top-down and bottom-up communication.

- Prioritize customer needs.

In the light of the results of the analysis of the business case proposed, it comes out that the QFD-AHP visualizes, in the most impartial way, the customers' requests, putting them into quality measurable characteristics and judging their rationality, productivity and adequacy to the market. Besides, the QFD points out the most critical characteristics deriving from the customer's real needs and from the position of the firm as to competition, simplifying the determination of the sections of improvement on which it is possible to intervene in order to fill the existing gaps.

In this work, some methods were realized which allowed to simplify the phase of analysis of the data contained in the "house of quality", and, therefore, brought about a reduction in the times of development of the project. Particularly, through the methodology employed for the valuation of the matrix of correlation, a procedure was set up, which, owing to the experimental verification, fulfilled, has allowed to:

- Make the filling of the table of correlations among the functional characteristics of the product easier.

- Verify automatically the presence of functional characteristics and/or customer's needs not connected with other needs and/or functional characteristics.

- Determine the minimal whole of functional characteristics which are connected with all the customer's requisites.

Besides, from the analysis of the results obtained, it came out that it:

- Allows to have at our disposal a shared definition of the products of the factory expressed in functional terms (profile of the product). 
- Allows to work in teams efficiently and without waste of time.

- Keeps the functional and technical characteristics separate, without any risk of binding the progress of the project.

- Allows to define in time all the functional specifications.

- Represents the base for comparing different alternatives of the project as to the value perceived by the market.

- Represents the base for a comparison with competition: it is possible to effect a direct comparison, or, also, to have elements in order to establish the sale price of the new product, so as to assure a sufficient competitive advantage.

The proposed model does not eliminate subjectivity completely - however, subjectivity elimination is not an attainable or desirable goal. The advantage of the proposed analytic model is that it adds quantitative precision to an otherwise ad hoc decision-making process.

Further development could be oriented in analyzing more complex case studies and in introducing the risk, cost and opportunity control in AHP hierarchy.

\section{References}

Akao, Y., Mazur, G.H., 2003. The leading edge in QFD: Past, present, and future. International Journal of Quality and ReliabilityManagement, Vol. 20, No. 1, pp. 20-35.

Bhattacharya, A., Sarkar, B., Mukherjee, S.K., 2005. Integrating AHP with QFD for robot selection under requirement perspective. International Journal of Production Research, Vol. 43, No. 17, pp. 3671-3685.

Chan, L.K., Wu, M.L., 2002. Quality function deployment: A literature review. European Journal of Operational Research, Vol.143, No.3, pp. 463-497.

Chan, L. K., \& Wu, M. L. 2005. A systematic approach to quality function deployment with a full illustrative example. Omega, Vol. 33, No. 1, pp. 119-139.

Chen, C. C., 2009. Integration of quality function deployment and process management in the semiconductor industry. International Journal of Production Research, Vol. 47, No. 5, pp. 1469-1484.

Chin, K. S., Wang, Y. M., Yang, J. B., \& Poon, K. K. G., 2009. An evidential reasoning based approach for quality function deployment under uncertainty. Expert Systems with Application, Vol. 36, No. 3P1, pp. 5684-5694.

Chuang, P.T., 2001. Combining the analytic hierarchy process and quality function deployment for a location decision from a requirement perspective. International Journal of Advanced Manufacturing Technology, Vol. 18, No. 11, pp. 842-849.

Cohen, L., 1995. Quality function deployment: how to make QFD work for you. Addison-Wesley Publishing Company. United States of America

Cor P.M. Govers, 2001. QFD not just a tool but a way of quality management. International Journal Production Economics, Vol. 69, pp. 151-159.

Das, D., Mukherjee, K., 2007. Development of an AHP-QFD framework for designing a tourism product. International Journal of Services and Operations Management, Vol. 4, No. 3, pp. 321 - 344.

De Felice, F., Falcone D., 1999. Definition of the specifications of a filter in ceramic material by the employment of the Quality Function Deployment. ECEC'99 European Concurrent Engineering Conference 1999 - SCS, Erlangen- Norimberga (Germany).

De Felice, F., Petrillo, A., 2009. Proposal of a new model for the optimization of the organizational process in industrial company through the application of the Analytic Network Process. 6th International Conference on Modelling \& Applied Simulation, Porto de la Cruz (Tenerife).

Han S.B., Chen S.K., Ebrahimpour M., Sodhi M.S., 2001. A conceptual QFD planning model. International Journal of Quality \& Reliability Management, Vol. 18, No. 8, pp. $796-812$.

Juran, J.M., 1993. Quality planning and analysis: from product development through use. 3th ed. McGraw-Hill, Inc. United States of America

Hanumaiah, N., Ravi, B., Mukherjee, N.P., 2006. Rapid hard tooling process selection using QFD-AHP methodology. Journal of Manufacturing Technology Management, Vol. 17, No. 3, pp. 332-350.

Ho, W., 2008. Integrated analytic hierarchy process and its applications - A literature review. European Journal of Operational Research, Vol. 186, pp. 211-228.

Hsiao, S.W., 2002. Concurrent design method for developing a new product. International Journal of Industrial Ergonomics, Vol. 29, No. 1, pp. 41-55.

Köksal, G., Eğitman, A., 1998. Planning and design of industrial engineering education quality. Computers and Industrial. Engineering, Vol. 35, No. 3-4, pp. 639-642.

Kwong, C.K., Bai, H., 2002. A fuzzy AHP approach to the determination of importance weights of customer requirements in quality function deployment. Journal of Intelligent Manufacturing, Vol. 13, No. 5, pp. 367-377.

Lam, K., Zhao, X., 1998. An application of quality function deployment to improve the quality of teaching. International Journal of Quality and Reliability Management, Vol. 15, No. 4, pp. 389-413.

Li, Y., Tang, J., Luo, X., Xu, J., 2009. An integrated method of rough set, Kano's model and AHP for rating customer requirements' final importance. Expert Systems with Applications, Vol. 36, pp. 7045-7053. 
Lin, M.C., Wang C.C., Chen, M.S., \& C. Chang, A., 2008. Using AHP and TOPSIS approaches in customer-driven product design process. Computers in Industry, Vol. 59, No. 1, pp. 17-31.

Partovi, F.Y., 1999. A quality function deployment approach to strategic capital budgeting. The Engineering Economist, Vol. 44, No. 3, pp. 239-260.

Ramanathan, R., \& Jiang, Y. F., 2009. Incorporating cost and environmental factors in quality function deployment using data envelopment analysis. Omega, Vol. 37, No. 3, pp. 711-723.

Saaty, T.L., 1980. The Analytic Hierarchy Process. McGraw-Hill, New York NY.

Saaty, T.L., 2001. Decision making with independence and feedback: The Analytic Network Process, Pittsburgh, RWS Publications.

Saaty, T.L., 2005. Theory and Applications of the Analytic network Process: decision making with benefits, opportunities, costs, and risks. Pittsburg, PA: RWS Publications.

\section{Biographical notes}

F. De Felice, Professor at the Faculty of Engineering of the University of Cassino, board member of several international organizations and responsible for scientific research and training in industrial plants. Holder of the course planning and management of industrial plants. The scientific activity developed through studies and researches on problems concerning industrial plant engineering. Such activity ranges over all fields from improvement of quality in productive processes to the simulation of industrial plants, from support multicriteria techniques to decisions (Analytic Hierarchy Process, Analytic Network Process), to RAMS Analysis and Human Reliability Analysis. The main courses, both curricular and specialistic for territorial businesses in which he is involved are: Safety of Industrial Plants, Industrial Production Management, Industrial Simulation, Human Reliability Analysis. General Secretary of the Analytic Hierarchy Process AHP Academy - International Association for the promotion of multi-criteria decision making methods.

A. Petrillo is a degree in Mechanical Engineering, now $\mathrm{PhD}$ at the Faculty of Engineering of University of Cassino where she conducts research activities on Multi-criteria decision analysis (MCDA), Industrial Plant and Quality Engineering at the Department of Mechanism, Structures and Environment of University of Cassino.

Received August 2010

Accepted December 2010

Final acceptance in revised form December 2010 